\section{Dental lead appointment announced}

Health Education England (HEE) has announced that Malcolm Smith is the new Chair of HEE's Advancing Dental Care (ADC) programme.

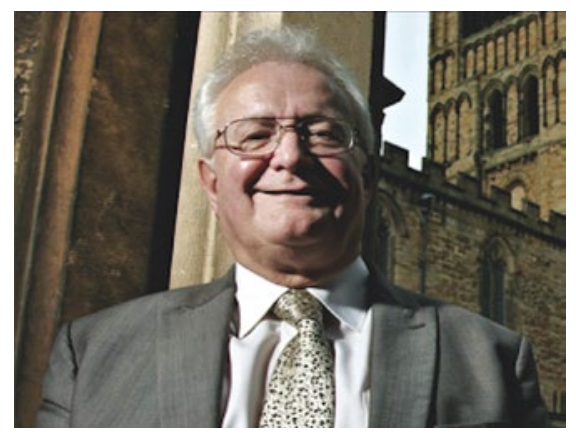

Malcolm Smith takes on the position following the retirement of Nicholas Taylor at the end of 2018.

Malcolm, who has a wealth of experience in dental education commissioning and training as Postgraduate Dental Dean for HEE North East, will drive forward the ADC programme into its second phase over 2019-2021, ensuring close alignment with the priorities outlined in the Long Term Plan for the NHS.

Leading on a broad programme which is designed to deliver the recommendations of the 2017-18 Advancing Dental Care Review, Malcolm will take an evidence-based approach to develop dental training that responds to the changing needs of patients and services, in a prevention-oriented integrated NHS, said HEE.

Malcolm said: 'I feel immensely privileged to be appointed to lead this important piece of work as I passionately believe that we have a duty to develop innovative structures and models of education and training, not only to support the delivery of excellent oral healthcare for patients but also to create meaningful and flexible career structures for the whole dental team.

'With the Long Term Plan for the NHS setting a clear strategic direction for the service and a strong commitment to develop the workforce, the timing couldn't be more appropriate to work with partners across the system to futureproof the dental workforce for generations to come.

'I look forward to working closely with colleagues, dental organisations, other stakeholders and patients so that, working together, we can produce models and pathways to enable oral health to take its rightful place in the holistic healthcare improvement.'

\section{New review management system launching}

It is easy to feel afraid of reviews, especially if you see a negative one, so Dental Design is launching its new review management system EasyReview - at the British Dental Conference and Dentistry Show 2019, co-located with the Dental Technology Showcase.

The company is inviting delegates to come to the launch and hear its 15-minute talk repeated throughout both days of the show, with the dental marketing experts discussing how to deal with negative reviews.

Online reviews can improve your search engine ranking and boost your practice's internet presence, which is why

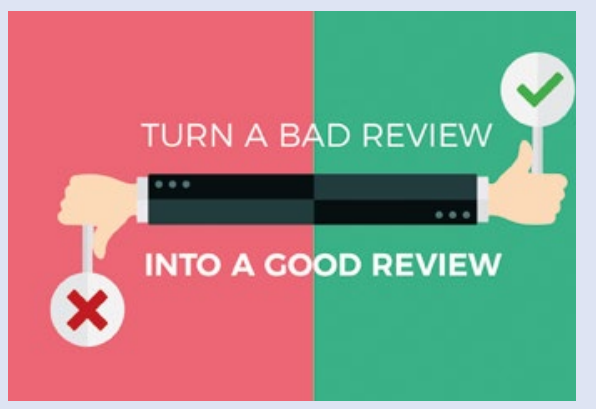

practitioners should always embrace negative reviews.

The talks will take place at stand D4.

To find out more about Dental Design's services, visit https://dental-designproducts.co.uk/or email enquiries@ dental-design.co.uk or call 01202677277.

\title{
Latest touchscreen X-rays
}

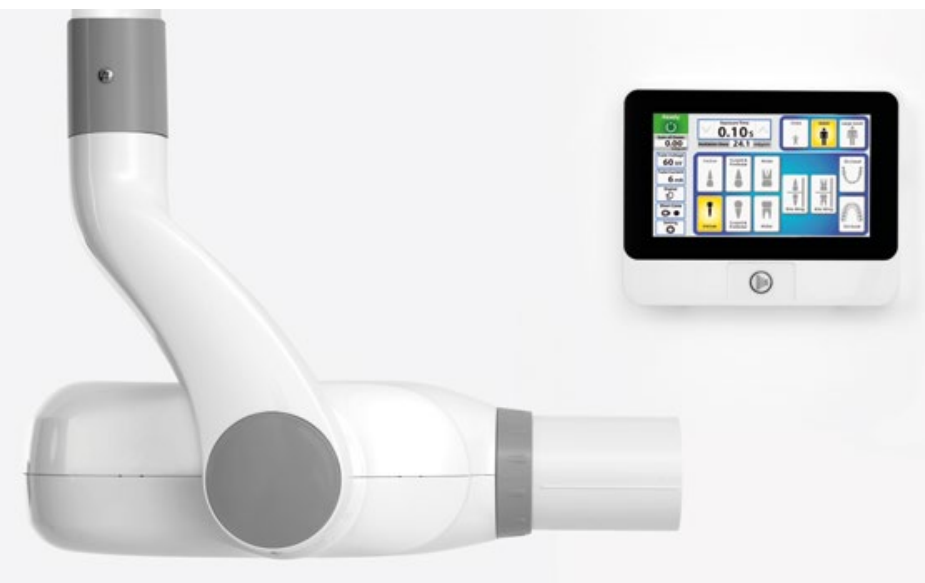

Belmont Touch is the new touchscreen $\mathrm{x}$-ray from Belmont and despite its technology being advanced, the product could not be simpler to use.

The easy-clean screen produces instant error code reports and has multi-lingual functionality. It also switches into sleep mode' to conserve energy and contains a USB port and handheld exposure switch which can be wall mounted.

Belmont Touch is also aesthetically appealing and has a zero-drift scissor-arm, which means it can be neatly stowed away against the wall when not in use.

Belmont Touch is compatible with any type of digital imaging system. Not only does it reduce the soft $\mathrm{x}$-rays absorbed by the tissues, making it safer and more reassuring for patients, but the tube voltage, current and exposure time can all be selected according to the individual clinical need, helping to avoid unnecessary exposure to radiation.

Offering a minimum exposure time of just 0.01 seconds, the Belmont Touch preprogrammed timer is selectable for digital systems and two different types of films.

A total of 16 film speeds are available and the lightweight, compact, easy to hold tube head enables the operator to align the tube accurately every time for re-producible, high contrast, crisp radiographs with excellent image quality.

More information is available by calling 02075150333 or e-mailing dental@takara.co.uk. 